\title{
EL SILENCIO TERAPÉUTICO: ENTRE LA OBJETIVIDAD Y LA SUBJETIVIDAD ${ }^{\mathrm{I}}$
}

\author{
THERAPEUTIC SILENCE: \\ BETWEEN OBJECTIVITY AND SUBJECTIVITY
}

\author{
JULIO ARMIJO NÚÑEZ \\ Médico Psiquiatra \\ julio.armijo@mail.udp.cl \\ Universidad Diego Portales, Chile \\ Instituto Chileno de Trastornos de Personalidad
}

Cómo citar este artículo:

ARMIJO, J. "El silencio terapéutico: entre la objetividad y la subjetividadt" en Palabra y Razón. Revista de Teología, Filosofía y Ciencias de la Religión. № 19 Julio 2021, pp I17-126 https://doi. org/10.29035/pyr.19..II7

I Agradezco al psiquiatra y psicoanalista Dr. Benny Oksenberg y a la Psicóloga Yael Klaber por su amable revisión de este escrito. 
Dedico este texto como un momento de silencio a la memoria del filósofo, psiquiatra y psicoterapeuta Rafael Parada Allende, profesor de la Universidad de Chile y Universidad Diego Portales; quien recientemente ha fallecido. Él amablemente transmitió sus conocimientos a mí y a otros psiquiatras, psicólogos y psicoterapeutas del Instituto Psiquiátrico José Horwitz Barak y revisó mi primer artículo escrito junto al filósofo Gonzalo Núñez.

Sigmund Freud buscó anhelos y motivaciones inconscientes de nuestra conducta. Comenzó en sus primeros años mediante métodos sugestivos (hipnosis) y más tarde, por medio del desarrollo de un método de asociaciones libres, construyó su teoría de la técnica y elaboró recomendaciones sobre la práctica analítica ${ }^{2}$. Lo anterior ocurre dentro de un paradigma cultural-científico de la época: una sociedad capitalistaliberal-burguesa brillante por los adelantos alcanzados por la ciencia, además de profundamente convencida de la posición central de Europa ${ }^{3}$.

Bajo este paradigma se distinguía claramente el sujeto del objeto de modo que Freud inicialmente afirma que la función del analista era observar e interpretar los conflictos inconscientes del paciente (entendidos hasta ese momento como la presencia de un impulso que ha quedado subsumido al inconsciente mediante un mecanismo de defensa llamado represión y que puede retornar en forma de síntomas, sueños, lapsus o actos fallidos) principalmente a través de un método de asociaciones libres. Es decir, tal como plantea Freud:

[La capacidad de] suprimir la vigilancia de las puertas de la conciencia [a través de] participarle todo cuanto se les pase por la cabeza, aunque les parezca que no es importante, o que no viene al caso, o que es disparatado; por el contrario, les pide con particular énfasis que no excluyan de la comunicación pensamiento u ocurrencia algunos, por más que los avergüence o les resulte penosos hacerlo. ${ }^{4}$

Se agregaría a su método la interpretación de manifestaciones del inconsciente en el sueño evidenciándose en el contenido manifiesto del sueño un contenido latente que por medio de mecanismos de

2 Cf., P. M. BROOMBERG. Awakening the Dreamer: Clinical Journeys. The Analityc Press: Londres, 2006, pp. I08-II4.

3 Cf., E. HOBSBAWN. Historia del siglo XX. Paidos: Buenos Aires, 2016, pp. I2-I6.

4 S. FREUD. "El método Psicoanalítico de Freud" en La Técnica Psicoanalítica. Amorrortu: Buenos Aires, 2015, p. 33. 
condensación, desplazamiento y simbolización transformarían impulsos y conflictos inconscientes en imágenes de sueño. ${ }^{5}$

Finalmente, la interpretación de las apariciones de las manifestaciones de la vida psíquica no consciente en la transferencia es un concepto de vital importancia. En su texto Sobre la dinámica de la Transferencia, Freud alude a que solo una parte de las tendencias que determinan la vida erótica ha realizado una evolución psíquica completa de modo de estar vuelta hacia la realidad y a una disposición de la personalidad consciente. Por otro lado, otra parte de tales tendencias libidinales quedan detenidas en su desarrollo por el veto de la personalidad consciente $-\mathrm{y}$ de la misma realidad $-\mathrm{y}$ solo han podido desplegarse en la fantasía o permanecido confinadas en lo inconsciente, siendo totalmente ignoradas por la consciencia de la personalidad: "El individuo cuyas necesidades eróticas no son satisfechas por la realidad, orientará representaciones libidinosas hacia toda nueva persona que surja en el horizonte, siendo muy probable que las dos porciones de su libido, la capaz de consciencia y la inconsciente, participen en este proceso". ${ }^{6}$ Es natural para Freud que esa carga de libido se orientase también a la persona del médico (el terapeuta) y que se incluya a este dentro de las 'series psíquicas'7 que el paciente ha formado. A ello le denominó transferencia.

Este es el primer momento del silencio: aquello que ha quedado reprimido/escindido, albergado en el inconsciente, silenciado al acceso de la personalidad consciente, pero que podría ser visualizado en un 'retorno de lo reprimido' en la transferencia. ${ }^{8}$ Stratchey, discípulos de Freud, desarrolla mayor trabajo en torno a la transferencia aludiendo también a la existencia de una transferencia negativa, es decir, "además de los sentimientos de amor, habían sentimientos hostiles que

5 Cf., S. FREUD. La Interpretación de los Sueños (vol.I). Amorrortu: Buenos Aires, 2018.

6 S. FREUD. "Sobre la Dinámica de la Transferencia" en La Técnica Psicoanalítica, pp. Io9-II4.

7 Desde La etiología de la histeria (1896) en que la etiología traumática de la neurosis cobraba relevancia - luego lo sería la fantasía proyectada del Complejo de Edipo- que Freud consideraba que "la cadena de asociaciones posee siempre más de dos elementos, y las escenas traumáticas no forman series simples, como las perlas de un collar, sino conjuntos ramificados, de estructura arbórea, pues en cada nuevo suceso actúan como recuerdos dos o más anteriores" (S. FREUD. "La Etiología de la Histeria" en Obras Completas I. Amorrortu: Buenos Aires, 20I3). Años más tarde en "Lecciones de introducción al psicoanálisis" (I9I6), surgiría la idea de que son series complementarias las que se superponen en la etiología de la neurosis: "Desde el punto de vista etiológico, las enfermedades neuróticas pueden ordenarse en una serie en la que los dos factores, constitución sexual e influencias exteriores, o si se prefiere, fijación de la libido y frustración, se hallan representados de tal manera, que cuando uno de ellos crece, el otro disminuye" (S. FREUD. "Conferencias de Introducción al Psicoanálisis" en Obras Completas XV. Amorrortu: Buenos Aires, 2013).

8 Cf., S. FREUD. "Recordar, Repetir y Reelaborar" en La Técnica Psicoanalítica, p. 193. 
naturalmente estaban lejos de asistir los esfuerzos del analista". ${ }^{9} \mathrm{La}$ confirmación de este tipo de transferencia se hizo tan importante como el descubrimiento de que la misma transferencia -tanto negativa como positiva- podía ser analizada y que "la parte más importante de todo el tratamiento era el análisis de dicha transferencia". ${ }^{\text {io }}$

Tiempo más tarde aparecerían nuevos conceptos como la identificación proyectiva que, en la teoría de relaciones de objeto de Melanie Klein, alude a un mecanismo de defensa primitivo del bebé para defenderse de su agresión intrínseca que proyecta al objeto (el pecho de la madre) y que genera ansiedades muy profundas persecutorias. En la identificación proyectiva como forma especial de identificación, las partes malas del yo son escindidas y proyectadas dentro del objeto que pasan a ser sentidos como un perseguidor que contiene los aspectos malos del yo y al cual no se le percibe como separado, sino como un yo malo ('malo' en el sentido de los aspectos agresivos, persecutorios, devaluados, que son necesarios de controlar para no ser atacado). ${ }^{I I}$

Si bien Melanie Klein concibió con fundamental importancia este fenómeno y puso énfasis en la fantasía intra psíquica del infante. Este punto abre una puerta fundamental a la participación del terapeuta en la transferencia donde -identificación proyectiva mediante- esas partes malas pudiesen quedar proyectadas transformándolo en un objeto agresivo y persecutorio (o de amor e idealización) en la fantasía del paciente. Por lo demás, una defensa excesiva de este tipo frente a las angustias persecutoria generaría una identificación prematura con el objeto ambivalente amado que cierra el espacio a la formación de símbolos e inhibe el desarrollo del yo. ${ }^{12}$

He aquí entonces donde años posteriores a Freud y su desarrollo del concepto de contratransferencia (como la reacción inconsciente del analista a la transferencia del paciente) se abre el espacio para el profundo análisis de la subjetividad del terapeuta. ${ }^{\mathrm{I}}$ El uso de la contratransferencia como un instrumento de observación e interpretación, hacen que el

9 J. STRATCHEY, "La naturaleza de la acción terapéutica del psicoanálisis" en Revista Psicoanalítica. 5 (1948), p. 95I.

Io S. FREUD. “Sobre la dinámica...”, p. II4.

II Cf., M. KLEIN. "Nota sobre algunos mecanismos esquizoides” en Obras completas Melanie Klein: Envidia y Gratitud y otros trabajos. Paidos: Barcelona, I946, pp. I5-I6.

I2 Cf., M. S. DIAZ, "Revisando el concepto de identificación proyectiva Kleiniano desde una perspectiva intersubjetiva" en Revista Chilena Psicoanalítica. 32/I (20I5), pp. 2I-35.

I3 Cf., S. FREUD. "Las Perspectivas Futuras de la Tearapia Psicoanalítica" en La Técnica Psicoanalítica, pp. 57-74. 
terapeuta no solamente observe e interpreta lo que percibe en el paciente, sino que incluye los datos provenientes de su observación respecto de sí mismo, de sus reacciones emocionales y de la posible conexión entre estas y lo que existe en el mundo interno del paciente: "la respuesta total del analista". ${ }^{14}$ Por lo tanto, el ideal a ser alcanzado sería la observación de la subjetividad del paciente y analista, ampliando la idea inicial de una pretendida objetividad planteada a la luz de la época en que Freud comenzó a desarrollar su pensamiento. Sin embargo, dicha posibilidad no sería factible sin el silencio del terapeuta. Así, tal como plantea Otto Kernberg, "el afecto predominante en la interacción (terapeuta-paciente) refleja las fantaseadas interacciones subyacentes interactuando entre Self y objeto que están siendo incautadas en la transferencia". ${ }^{15}$

Dicho despliegue no podría ser alcanzado sin la disposición de un contrato que es la base de toda transacción en la cual hay algún tipo de intercambio. ${ }^{16}$ Este contrato se da en un encuadre psicoanalítico dispuesto por Freud de neutralidad y abstinencia. ${ }^{17}$ En este sentido, llamamos neutralidad a la capacidad de mantenernos en una posición equidistante respecto a las fuerzas en conflicto dentro de la mente del paciente. Tal como plantea Eizirik:

La postura, tanto en el comportamiento como en lo emocional, a partir de la cual el analista en su relación con el paciente observa, sin perder la necesaria empatía, manteniendo una distancia posible en relación al material del paciente y su transferencia; a la contratransferencia y a su propia personalidad; a sus propios valores; a las expectativas y presiones del mundo externo, y a la (las) teoría(s) psicoanalítica(s). ${ }^{18}$

Por otro lado, la abstinencia, como la capacidad de mantenernos sin 'gratificar' las pulsiones del paciente manifiesta de modo inconsciente en la transferencia, la consideramos parte de la neutralidad técnica ${ }^{19}$. He

\footnotetext{
I4 M. LITTLE. Transferencia Neurótica \& Transferencia Psicótica. Pólvora: Santiago, 198I, pp. 95-98. I5 O. KERNBERG, "Therapeutic Implications of Transference Structures in Various Personality Pathologies" en Journal of the American Psychoanalytic Association. 67/6 (2019), p. 970.

I6 Cf., H. ETCHEGOYEN. Fundamentos de la Técnica Psicoanalítica. Amorrortu: Buenos Aires, 2010. pp 76-90.

I7 S. FREUD. "Consejos al médico sobre el tratamiento psicoanalítico" en La Técnica Psicoanalítica, pp. I23-I38.

I8 C. EIZIRIK, "Entre la objetividad, la subjetividad y la intersubjetividad: ¿Aún hay lugar para la neutralidad analítica?" en Aperturas Psicoanalíticas: Revista Internacional de Psicoanálisis, I2 (2002), disponible en: http://www.aperturas.org/articulo.php?articulo=00002I2\#contenido.

I9 Cf., S. FREUD. "Puntualizaciones sobre el amor de Transferencia" en La Técnica Psicoanalítica, pp. 197-218.
} 
aquí un segundo momento de silencio que señala André Green:

[D]el mismo modo como el sueño es el guardián del dormir, el analista es el guardián del encuadre cuyo principal parámetro es el silencio [...]. El analista es políglota, entiende el lenguaje del sueño, de la fantasía, del lapsus, del acto fallido, o de todo lo que se nutra del estilo inconsciente. Sin duda, el silencio es el fondo sobre el cual se desarrollan las figuras de las armonías significantes (y sus disonancias) [...] Un modelo de la actividad psíquica se proporciona entonces: organización, desorganizaciónborradura, reorganización. Es aplicable a toda forma de actividad psíquica. Este modelo reformula nociones que nos son similares: deseo-represión-retorno de lo reprimido. En la sesión, el silencio corresponde al tiempo medio, mientras que la interpretación atestigua el tercer tiempo. Es importante recordar la no linealidad del trabajo psíquico, su polifonía. Es el sentido de la asociatividad analítica. $^{20}$

Es el silencio del terapeuta - refiriéndonos a su capacidad de mantener neutralidad y abstinencia - el que permite el despliegue de las proyecciones inconscientes de las relaciones de objeto reprimidas o escindidas las que generan movimientos afectivos inconscientemente dirigidos hacia el terapeuta tal cual se dirigen al objeto original. A ello le llamamos transferencia: positiva según sean sentimientos provenientes de la vida erótica, negativa según sean sentimientos agresivos dirigidos hacia el terapeuta ${ }^{21}$. Es este conjunto de proyecciones inconscientes las que suscitan diferentes formas de contratransferencia en el terapeuta: concordante, cuando el terapeuta se identifica con el self del paciente; complementaria, cuando el terapeuta se identifica con el objeto. ${ }^{22}$

En un tercer momento, el silencio es una herramienta terapéutica. Cómo señala Margaret Little, el terapeuta encuentra un intervalo de tiempo entre las identificaciones que el analista tiene con su paciente. Esto se diferencia de la inmediatez con que el paciente siente las identificaciones con el analista que señala Little:

2o A. GREEN. "El silencio del Psicoanalista" en La nueva clínica Psicoanalítica y la teoría de Freud. Amorrortu: Buenos Aires, 1970. p. I42.

2I Cf., O. KERNBERG, “Therapeutic Implications...”, pp. 95I-986.

22 Cf., O. KERNBERG, "Notes on Countertransference" en Journal of the American Psychoanalytic Association. I3/I (1965), pp. 38-56. 
Si el analista las está experimentando como un hecho presente, está entonces interfiriendo con el crecimiento y desarrollo del paciente [...] cuando se introduce tal intervalo de tiempo, el paciente puede sentir su experiencia, de forma inmediata, libre de interferencia, $y$ dejar que se transforme en pasado para él también, de modo que pueda ocurrir una identificación nueva con su psicoanalista. ${ }^{23}$

En mi opinión, muchas veces es sólo el silencio lo que nos da este intervalo de tiempo, a veces infinitesimal; es el decidir 'elegir callar' - esto es, elegir el silencio- en lugar de gratificar la pulsión que inconscientemente - por medio de la identificación proyectiva - nos compele a realizar actos de habla como formas de no ser conscientes con las identificaciones con las relaciones de objeto proyectadas por el paciente.

El silencio del terapeuta permite las asociaciones del paciente por muy dolorosas que sean o por mucho malestar y devaluación en la contratransferencia y transferencia. Permite analizar lo que en reprimido o escindido está en el inconsciente en forma de díadas de relaciones de objeto y como se manifiesta de diversas formas en los actos en la relación terapéutica, las fantasías del paciente y su historia pasada. El silencio permite también esperar a interpretar gestos cotidianos que en un paciente pueden estar (o no) llenos de significados y abrir cadenas asociativas hacia la historia del pasado en el inconsciente. En palabras de André Green:

En la situación psicoanalítica, es posible distinguir diferentes intercambios entre paciente y analista en el interior del encuadre:

I. Lo dicho al paciente

2. Lo callado, no dicho y sabido, del paciente

3. Lo callado, no dicho y no sabido, del paciente

4. Lo inaudible y lo inaudito del paciente

5. Lo dicho del analista

6. Lo callado, no dicho y sabido, del analista

7. Lo callado, no dicho y no sabido, del analista

8. Lo inaudible y lo inaudito del analista. ${ }^{24}$

Aquí silencio y palabra son solidarios y conjuntos. La palabra vehiculiza el sentido del inconsciente: palabra plena en oposición a la

23 M. LITTLE. "La Contratransferencia y la Respuesta del Paciente" en Transferencia Neurótica \& Transferencia Psicótica. Pólvora: Santiago, 1981. pp. 82.

24 A. GREEN, "El silencio del Psicoanalista...", pp. I4I-I42. 
palabra vacía. El silencio, ambiguamente, recubre lo escondido, lo no sabido del paciente y el analista; lo inaudible — e inaudito - de cada uno de ellos. ${ }^{25} \mathrm{Al}$ respecto quisiera hacer dos comentarios (sin observar orden a la cronología de los autores).

Primero, Wilfred Bion desarrolló el concepto de 'capacidad negativa' como un estado mental de 'no saber', de no buscar en la memoria referentes parecidos o similares a lo que estamos observando o escuchando en el aquí y ahora de la sesión: "La memoria y el deseo pueden ser considerados como 'sentidos' pasado y futuro (análogos al concepto matemático de 'sentido' y aplicables indiferentemente al tiempo y al espacio) de la misma 'cosa'". ${ }^{26}$ La capacidad negativa consiste en renunciar al deseo y al recuerdo; al intento reduccionista de la comprensión objetual para entrar en relación con lo desconocido. Este modo de incluir la dimensión epistemológica de lo negativo constituye una nueva forma de abstinencia que Bion resume en su célebre frase 'sin memoria, sin deseo y sin comprensión'. Este estado de no saber nos lleva a la aceptación del caos para que en un segundo momento logremos encontrar un orden. De este modo, tolerando que situaciones incoherentes se vuelvan coherentes, suspendiendo el juicio sin buscar en las propias teorías, sin defenderse de lo no sabido a través de la memoria y el deseo. ${ }^{27}$ Quizás esta es una aproximación plausible hacia "lo callado, no dicho y no sabido, del paciente" ${ }^{28}$ Esta es otra forma del silencio en el terapeuta. Un silencio epistemológico y epistemogénico.

Segundo, en su texto El odio en la contratransferencia, Donald Winicott señala lo siguiente:

Por mucho que quiera a sus pacientes, el psiquiatra no puede evitar odiarlos y temerlos, y cuanto mejor sepa esto, menor será la incidencia del odio y el temor en su conducta respecto a los pacientes [...]. Ante todo, no debe negar un odio que realmente existe en el mismo [...]. El odio que está injustificado en el marco existente debe ser separado y mantenido en reserva, disponible para una eventual interpretación. ${ }^{29}$

25 Cf., A. GREEN, “El silencio del Psicoanalista...”, p. I42.

26 Cf., W. BION. Volviendo a Pensar. Horme: Buenos Aires, 1966.

27 Cf., D. MALPARTIDA, "De la Capacidad Negativa de Keats a la Capacidad Negativa del Psicoanálisis" en Revista Psicoanálisis. II (2013), pp. I23-I35.

28 A. GREEN, "El silencio del Psicoanalista...", p. I4I.

29 D. WINICOT, "El odio en la contratransferencia"en International Journal of Psychoanalysis. 30 (I949), pp.7I. 
He aquí un punto respecto al silencio en el terapeuta: poder albergar y contener emociones tan difíciles de reconocer como las sensaciones negativas hacia un paciente. Aunque estas podrían ser manifestaciones de proyecciones agresivas inconscientes del propio paciente, resulta ser importante separarlas de los sentimientos propios para lo cual la terapia personal es necesaria. Es un deber ético y técnico ser terapeutas capaces de tolerar la propia agresión: no negarla (lo inaudible y lo inaudito del analista ${ }^{30}$ ), sino actuar con ella y ser capaz de 'resistir' la agresión inconsciente de los pacientes sin deprimirse, sin negarlo, sin retirarse del campo ni vengarse; más bien, en silencio esperando el "timing" de la interpretación. ${ }^{31}$

Finalmente, el silencio del terapeuta podría ser visto como una 'regla del juego' que genera un espacio psicológico distintivo del espacio 'psicologizado-desritualizado' que circunscribe a la sociedad contemporánea donde, de acuerdo con Byung-Chul Han, se destruyen los espacios de juego objetivo en favor de las excitaciones afectivas de índole subjetiva. ${ }^{32}$ El filósofo suizo-alemán describe como la intimidad es la forma psicológica de la transparencia: se cree conseguir la transparencia del alma por el hecho de revelar los sentimientos y emociones íntimas, desnudando el alma públicamente. El modo como la cultura de la intimidad va unida a la caída de aquel mundo objetivo-público (que no es objeto de sensaciones o vivencias íntimas). De modo que según la 'ideología de la intimidad' planteada por el autor, las relaciones sociales son tanto más reales, cabales, creíbles y auténticas cuanto más se acercan a las necesidades de los individuos. El epítome sería el uso de aquellas redes sociales en las cuales los motores de búsqueda personalizados erigen en la red un absoluto espacio cercano en el que está eliminado el afuera. Allí nos encontramos solo con nosotros mismos y con nuestros semejantes sin la capacidad de delimitar nuestro 'sí mismo' ya que la cercanía del mundo digital nos presenta tan solo aquellas secciones de la realidad que 'me gustan', transformando la red en una esfera "íntima" o "zona de bienestar". En lugar de lo público, se introduce la publicación de la persona, lo que hace que la esfera pública se convierta en un lugar de exposición con una creciente des-ritualización y pérdida del carácter narrativo de la sociedad, la cual se vacía de sus formas que son los juegos, los rituales, las reglas objetivas, pues: "quien juega con otros se subordina a normas objetivas del juego y la sociabilidad del juego no descansa en la

3 Cf., A. GREEN, "El silencio del Psicoanalista...”, p. I42.

3I Cf., O. KERNBERG. Agression: In personality disorders and perversions. Yale University Press: New Haven, 1992.

32 B. HAN. La sociedad de la Transparencia. Herder: Barcelona, 2013. 
recíproca revelación propia”. 33

El silencio del terapeuta es un espacio de juego con reglas objetivas y a la vez un espacio ritual-ceremonial donde circulan signos objetivos: el encuadre y la técnica. En cierto aspecto, en el silencio el terapeuta está 'vacío y ausente' permitiendo delimitar al sujeto de 'sí mismo' — de la intimidad consigo mismo sin distancias - por medio de la proyecciones inconscientes de sus relaciones de objeto en la transferencia. Así, allí donde no surge ninguna imagen propia estable, ningún vacío, ninguna ausencia que distancie al sujeto de sí mismo, puede surgir el espacio inconsciente de una relación objetual interpretable en la que se encuentra anclada la estructura de personalidad del sujeto.

33 B. HAN. La socied $a d . . .$, pp. 69-70. 